\title{
Core Decompression and Biological Treatment in Osteonecrosis of the Hip due to Systemic Lupus Erythematosus, 8-year Follow-up: A Case Report
}

\author{
Sholahuddin Rhatomy ${ }^{1 *}$ (D), Ismail Hadisoebroto Dilogo² (D) \\ ${ }^{1}$ Department of Orthopaedic and Traumatology, Faculty of Medicine, Public Health and Nursing, Universitas Gadjah Mada, \\ Dr. Soeradji Tirtonegoro General Hospital, Yogyakarta, Indonesia; ${ }^{2}$ Department of Orthopaedic and Traumatology, Dr. Cipto \\ Mangunkusumo National Hospital, Faculty of Medicine, Universitas Indonesia, Jakarta, Indonesia
}

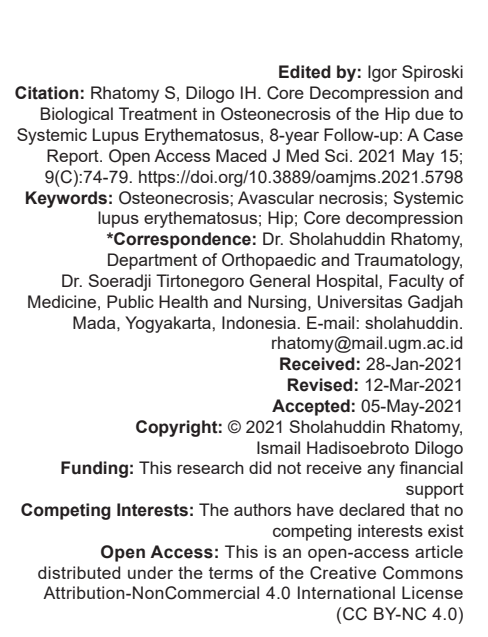

\begin{abstract}
BACKGROUND: Osteonecrosis most commonly affects the femoral head, especially in middle-aged adults. It can be caused by trauma, chronic inflammation, or infection. It leads to collapse of the entire femoral head and culminates with total hip replacement.

CASE REPORT: A 29-year-old female with systemic lupus erythematosus (SLE) had a chief complaint of bilateral hip pain. She was diagnosed with early osteonecrosis of the femoral head (FICAT stage II) using magnetic resonance imaging and core decompression surgery was performed using three small diameter $(4 \mathrm{~mm})$ drillings and added biological treatment. She was evaluated with a visual analog scale (VAS), Harris hip score (HHS), and plain radiography in the pre-operative stage and post-operative follow-up.

RESULTS: Functional outcome at 8-year follow-up showed improvement with significantly decreased VAS (pre-operative: 5, post-operative: 0), significant improvement of HHS from 52.725 points (poor) pre-operative to
\end{abstract} 92.025 points (excellent) post-operative, and subsided femoral head lesion.

CONCLUSIONS: Surgical decompression and biological treatment result in decreased intraosseous pressure and enhanced osteogenesis. It can restrict the SLE disease progression and limit the number of cell death.

\section{Introduction}

Avascular necrosis (osteonecrosis) of the femoral head can be caused by various etiologies. It can reduce the subchondral support on the articular surface which leads to joint collapse and osteoarthrosis. This phenomenon can occur in patients under 50 years old when joint replacement should be avoided. Avascular necrosis management varies from weight-bearing restriction, core decompression [1], [2], [3], [4], [5], osteotomy [6], non-vascularized structural graft [7], electrical stimulation [8], or more recently, and vascularized bone grafts [9].

Ohzono et al. reported that there were 78 out of 115 patients (68\%) with osteonecrosis of the femoral head who were treated non-operatively [10]. Mont et al. stated that the clinical outcome satisfaction of non-operative management was only $22.7 \%$ [11]. The clinical series shows that most hips with avascular necrosis develop into articular collapse and osteoarthrosis. Intervention therapy that can delay or prevent articular collapse occurrence will be very helpful.

Core decompression initially served as a diagnostic procedure, but nowadays, this procedure can be used as a management method of osteonecrosis because of its therapeutic benefits. This procedure has begun to increase due to its good outcomes, low morbidity, and reduced hospitalization. Core decompression can reduce the intraosseous pressure caused by interstitial edema, increasing vascularity, and slowing the tissue death progression in the femoral head. It can also relieve hip pain [5], [11]. Mont et al. reported that the progression of osteonecrosis was inevitable in 434 (36\%) of 1206 hips [11]. Stulberg et al., comparing between core decompression procedure and non-surgical treatment, reported the progression of necrosis on radiographic examination in 9 cases $(31 \%)$ of the 29 hips with core decompression and 20 cases $(77 \%)$ of the 26 hips with non-operative treatment [12]. In this study, we report a patient with bilateral hip osteonecrosis due to systemic lupus erythematosus 
(SLE) who was treated with core decompression and followed up clinically and with magnetic resonance imaging (MRI) examination after 8 years.

\section{Case Report}

A 29-year-old female came to the outpatient clinic on March 2012 with chief complaint of bilateral hip pain for the past 6 months. She complained of intermittent pain that was radiating into the groin and anteromedial thigh region. Her symptoms were aggravated by walking, stair climbing and she was unable to sit comfortably on the chair. Her pain was relieved by resting. The patient did not report numbness or paresthesia in her lower extremities. She also did not complain about bowel nor bladder dysfunction. The patient did not have the previous history of night sweats, fever, nor chills. The patient's gait showed an antalgic limp.

The patient had been diagnosed with SLE since 2011 and was prescribed corticosteroid treatment since April 2012 (2 months before surgery). In May 2012, the patient was diagnosed by a hospital in another country with hydrocephalus, then gamma knife surgery was performed with a VP shunt placed inside her brain.

Physical examination revealed the limitation in range of motion of the left and right hip due to pain. The worst pain was felt in the abduction and internal rotation. Functional outcome, according to Harris hip score (HHS), was 52.725 (poor). Range of motion of the knee was full. There was no pain or effusion on the knee joint. Lower limb neurological testing revealed normal reflexes and normal sensibility in both legs.

The patient was suspected with avascular necrosis of the bilateral hip with differential diagnoses of hip osteoarthritis or union fracture. She underwent plain radiography of the pelvis. The results showed that there were no abnormalities in the pelvis nor proximal femur (Figure 1). Then, we did MRI of the pelvis and

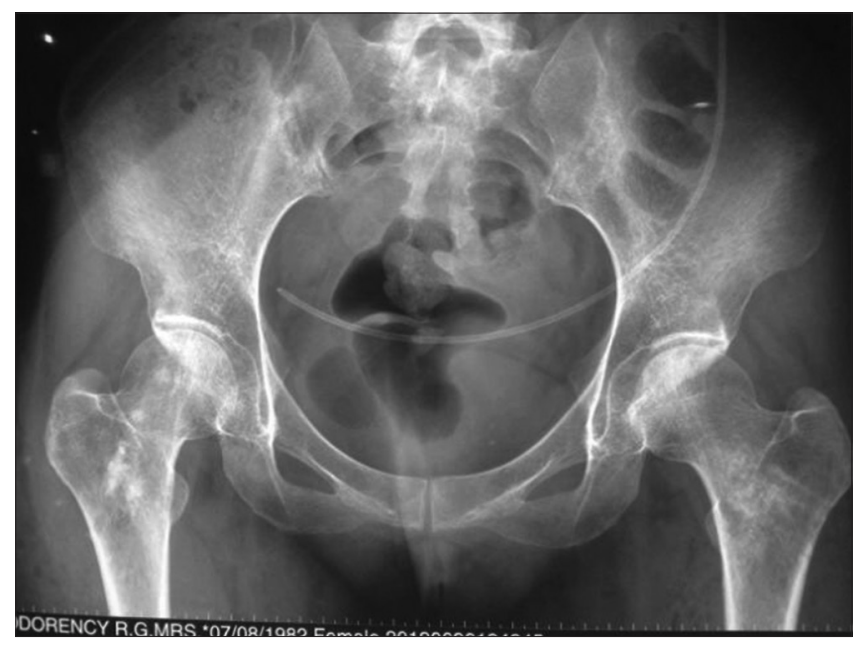

Figure 1: Pelvis X-ray (before surgery, June 26, 2012) proximal femur. The MRI showed a crescent sign that revealed a Ficat and Arlet stage 2 osteonecrotic lesion in the femoral head (Figure 2).

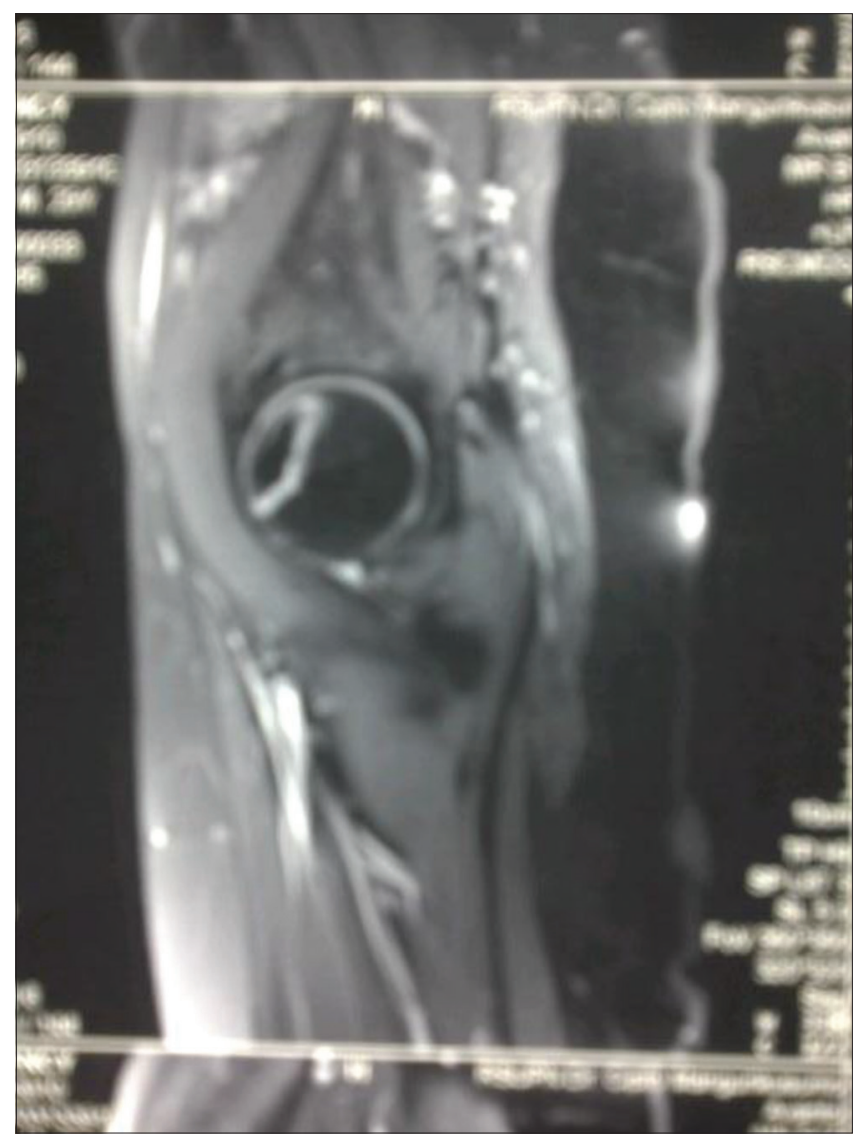

Figure 2: Magnetic resonance imaging of the right hip shows Crescent sign (March 7, 2012/before surgery)

Finally, we diagnosed the patient with avascular necrosis of the bilateral femoral head based on the clinical and radiological reports. The patient was subsequently scheduled for bilateral hip core decompression.

Core decompression under general anesthesia was done with 3 small diameters using $5.0 \mathrm{~mm}$ drill bits (for cannulated screw $7.3 \mathrm{~mm}$, DePuy Synthes). Parallel drillings were performed into the osteonecrotic portion of the femoral head with the fluoroscopy guiding. We placed biological treatment that mixture of bone marrow from the iliac crest (Figure 3), demineralized bone matrix, synthetic bone graft (hydroxyapatite), and recombinant human bone morphogenetic protein-2 (rhBMP-2) into the lesion. The patient was mobilized with a non-weight-bearing position and was discharged with a wheelchair.

Six months after surgery, the patient came to the outpatient orthopedic clinic. She had reached full weight-bearing and could do daily activity freely. Physical examination showed the range of motion of the hip was normal. Functional outcome, according to HHS, was excellent (91.025 points). According to HHS, a successful result is gained if there is an improvement of $\mathrm{HHS}>20$ points and stable implant radiographically 


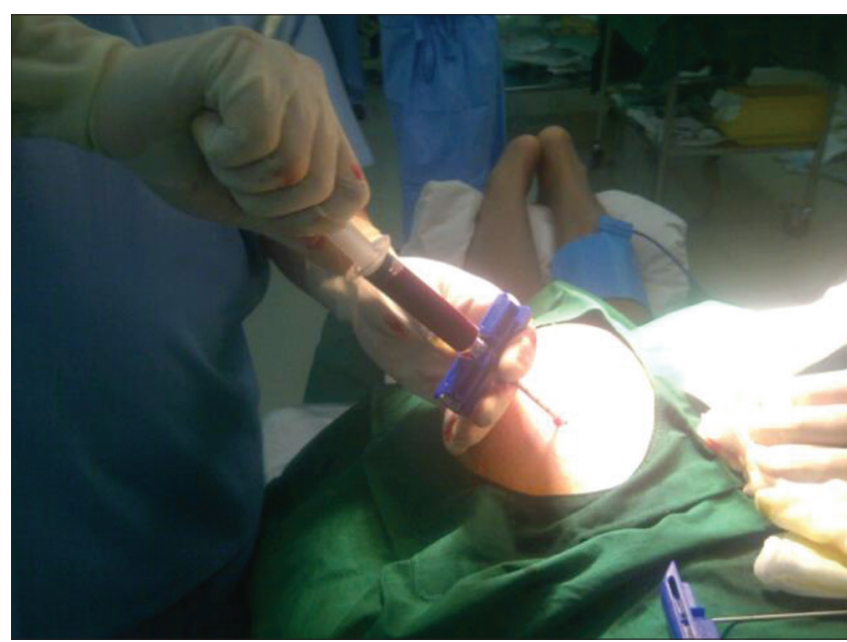

Figure 3: Bone marrow aspiration from iliac crest

plus no additional femoral reconstruction. Then, we performed another MRI examination. The MRI showed that the crescent sign on the femoral head was still there but had decreased in size compared to before surgery, and the femoral head cartilage was still good (Figure 4).

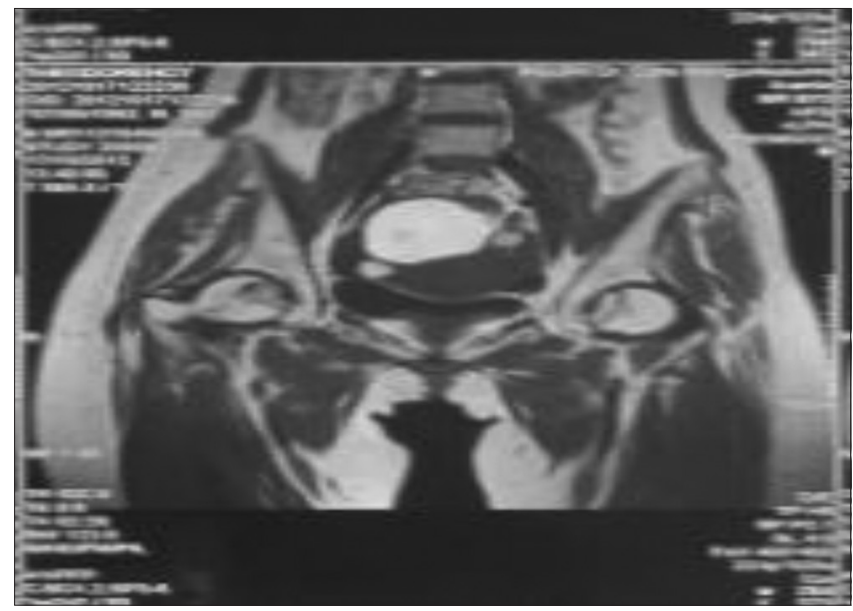

Figure 4: Magnetic resonance imaging has been taken 6 months after surgery (December 7, 2012)

Ten months after surgery, the patient came to the outpatient orthopedic clinic. The patient had maintained full weight-bearing and could do daily activity freely. Physical examination showed the range of motion of the hip was still normal. Functional outcome, according to HHS, was still excellent (92.025 points).

MRI examination showed that the crescent sign on the femoral head was still there but had decreased in size compared to the six-month follow-up, and the cartilage of the femoral head was still good (Figure 5).

Eight years after surgery, the patient came to orthopedic clinic. The patient can do full weightbearing, was pain-free and doing sports activities freely (Figure 6). Physical examination showed the range of motion of the hip was still in normal function. Functional outcome, according to HHS, was still excellent (92.025 points). MRI showed that the crescent sign on the femoral head was still there but had decreased in size

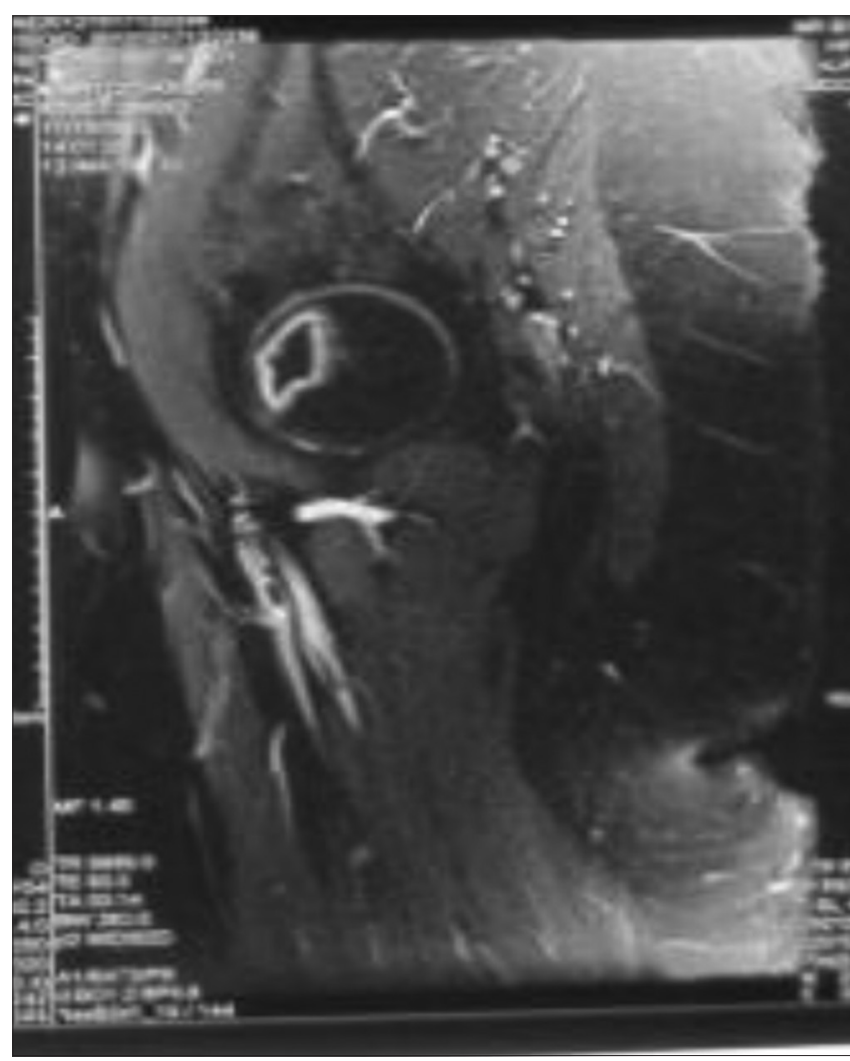

Figure 5: Magnetic resonance imaging has been taken 10 months after surgery (April 16, 2013)

compared to the 9 months follow-up, and the cartilage of the femoral head was still good (Figure 7 and Table 1).

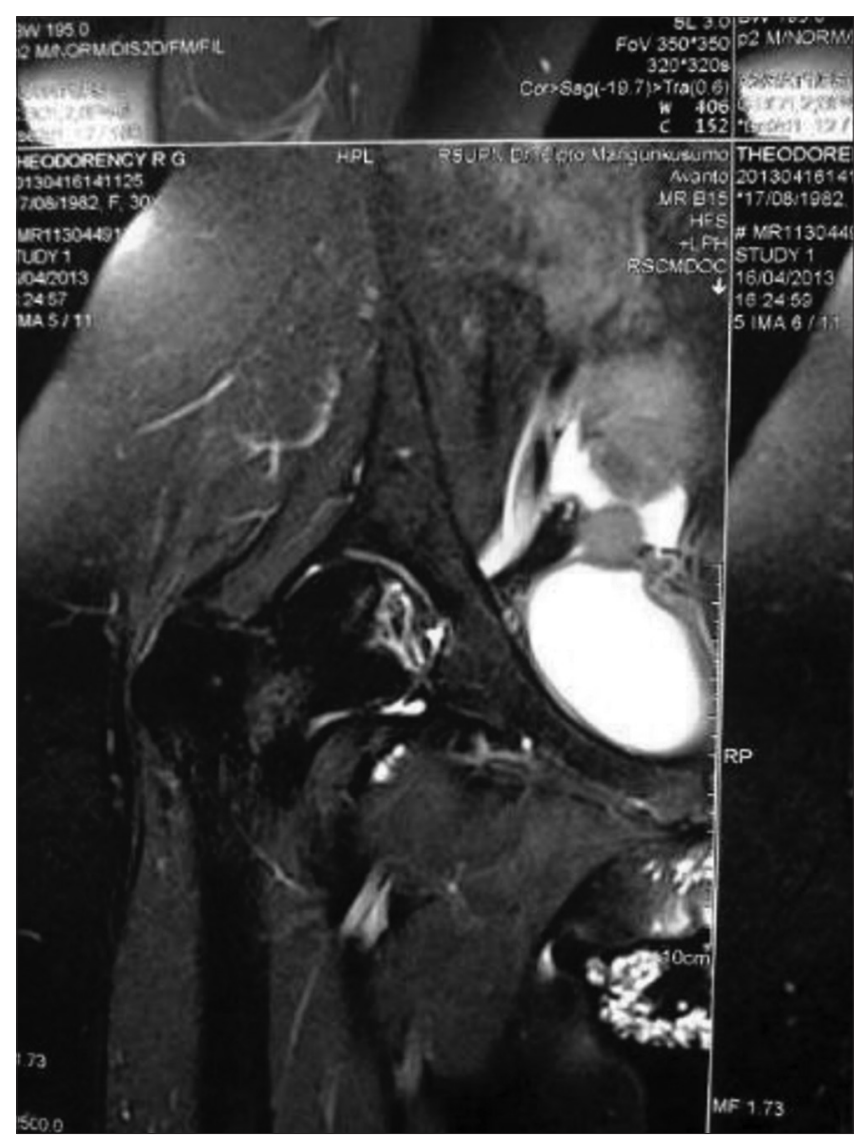

Figure 6: Clinical examination 8 years after surgery 


\section{Discussion}

In osteonecrosis and the late stages of osteoarthrosis, there are increments that develop increased intraosseous pressure and histological necrosis [13], [14]. Normal range of femoral head intraosseous pressure is between $24 \mathrm{mmHg}$ and 26 $\mathrm{mmHg}$. Femoral head intraosseous pressure can be as high as 43-49.9 mmHg in the case of osteonecrosis. Kiaer et al. reported that there were pathological intraosseous pressures if the pressure was above $30 \mathrm{mmHg}$ [15]. $\mathrm{PO}_{2}$ is decreased in osteonecrosis (average $44 \mathrm{mmHg}$ ) compared to normal (average $71 \mathrm{mmHg}$ ) [15]. Surgical core decompression can result in a significant decrease in intraosseous pressure and increased $\mathrm{PO}_{2}$ level. This procedure can also increase revascularization; therefore, the development of cell death can be prevented [16].

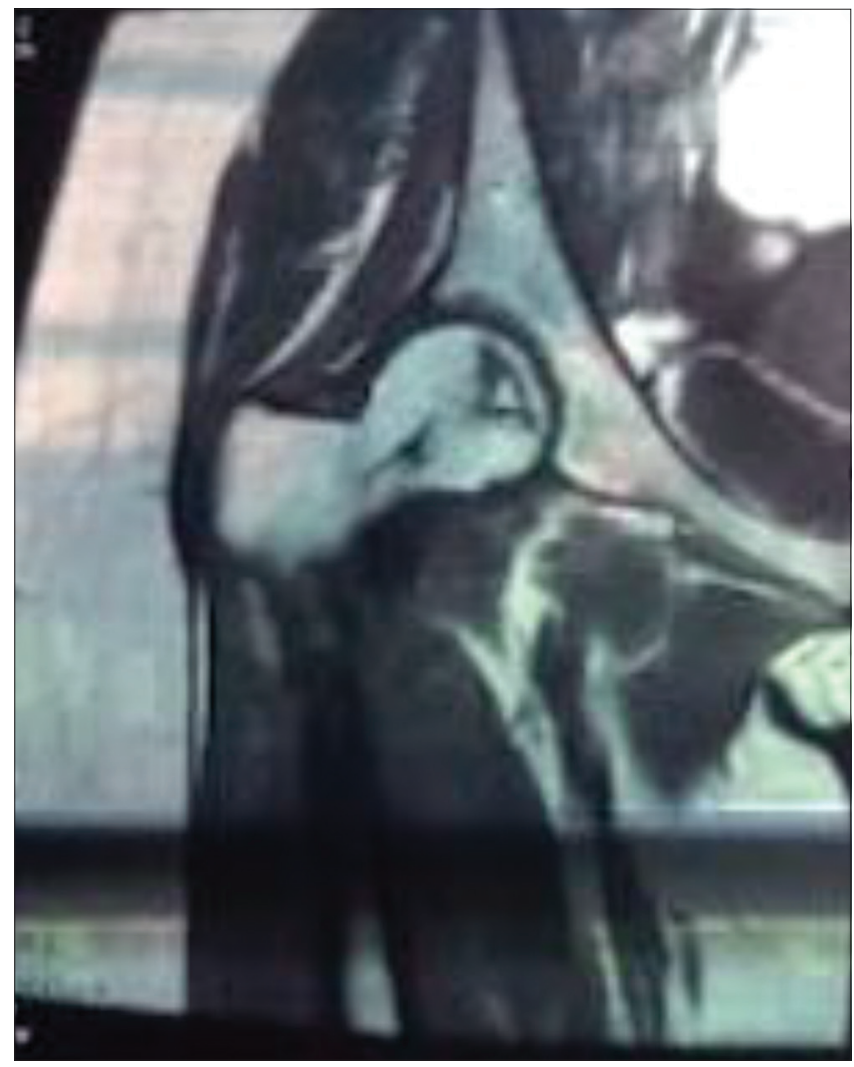

Figure 7: Magnetic resonance imaging have been taken 8 years after surgery

The patient presented here underwent both mechanic and biologic treatment. Mechanical treatment was performed with core decompression. Biological treatment was directed to enhance osteoblast differentiation and accelerate osteogenesis. We treated the patient with a combination of bone marrow from the iliac crest, demineralized bone matrix, synthetic bone graft (hydroxyapatite), and rhBMP-2.

Subchondral drilling is a variant of microfracture surgery in which a drill, burr, or Kirschner wire is used to create drill holes into the subchondral bone [16]. The defect is replaced by a hybrid of fibrocartilage and hyaline-like cartilage rather than the original hyaline
Table 1: Clinical and MRI finding before and after surgery

\begin{tabular}{|c|c|c|c|c|}
\hline $\begin{array}{l}\text { Outcome } \\
\text { Measurement }\end{array}$ & $\begin{array}{l}\text { Before } \\
\text { surgery }\end{array}$ & $\begin{array}{l}6 \text { month after } \\
\text { surgery }\end{array}$ & $\begin{array}{l}9 \text { month after } \\
\text { surgery }\end{array}$ & $\begin{array}{l}8 \text { years after } \\
\text { surgery }\end{array}$ \\
\hline $\begin{array}{l}\text { Pain visual } \\
\text { analog scale }\end{array}$ & 5 & 0 & 0 & 0 \\
\hline HHS & $\begin{array}{l}52,725 \\
\text { (Poor) }\end{array}$ & 91,025 (Excellent) & 92,025 (Excellent) & 92,025 (Excellent) \\
\hline $\begin{array}{l}\text { MRI } \\
\text { Examination }\end{array}$ & $\begin{array}{l}\text { Crescent } \\
\text { Sign }(+)\end{array}$ & $\begin{array}{l}\text { Crescent Sign }(+) \text {, } \\
\text { decrease in large, } \\
\text { cartilage of femoral } \\
\text { head still good }\end{array}$ & $\begin{array}{l}\text { Crescent Sign }(+) \text {, } \\
\text { decrease in large, } \\
\text { cartilage of femoral } \\
\text { head still good }\end{array}$ & $\begin{array}{l}\text { Crescent Sign } \\
(+), \text { decrease in } \\
\text { large, cartilage of } \\
\text { femoral head still } \\
\text { good }\end{array}$ \\
\hline
\end{tabular}

cartilage. Some disadvantages of the replacement tissue are caused by its component that mainly consists of type I collagen, which has lower biomechanical properties but still is better at resisting tensile forces more than compressive forces as found in a typical joint [16]. We provided a composite that consisted of bone marrow from the iliac crest, demineralized bone matrix, synthetic bone graft (hydroxyapatite) and rhBMP-2 to prevent the biomechanical failure and increase hyaline cartilage formation.

Autologous bone marrow in vitro has been shown to restore full-thickness defects by reconstitution of the underlying subchondral bone and formation of hyaline cartilage [16]. Bone morphogenetic proteins (BMPs) were discovered to have a bone-inductive chemical property in the bone matrix. rhBMP-2 was shown to stimulate bone formation under various conditions. Animal and human studies have revealed the successful use of rhBMP-2 to stimulate bone regeneration for bone defect treatment. Biomaterials including hydroxyapatite, hydroxyapatite, tricalcium phosphate, and calcium sulfate can be used as an rhBMP-2 carrier matrix because BMP-2 needs a carrier to be activated in the tissue destination. BMP-2 is released into the surrounding environment and enhances the formation of new bone [17].

Hydroxyapatite provides good adhesion to the local tissue due to the surface chemistry and has been shown to enhance osteoblast proliferation and differentiation (osteoconductive components) [18]. Demineralized bone matrix can function as both osteoconductive and osteoinductive components. It is composed of demineralized bone from a human donor in a biocompatible carrier. Demineralized bone matrix is produced by the removal of minerals from cortical bone [19].

The outcome was satisfactory both clinically and radiologically. Our patient can freely do daily activities with full weight-bearing. Functional outcome, according to HHS, was increased more than 20 points (from 52.725 (poor) pre-operative into 92.025 (excellent) 8-years post-operative). Plain radiological examination of the pelvis was normal and MRI showed the crescent sign on the femoral head was still there but had decreased in size compared to before the surgery and also the femoral head cartilage was still good.

Recent literature described that the overall success rate of core decompression was from $60 \%$ to 
$80 \%$ at a 5-10-year follow-up. The availability of MRI has helped excellently for early diagnosis and evaluation at 5-year follow-up. MRI is rated as the most accurate radiological modality in evaluating osteonecrosis [20].

The evidence of lesion size reduction is a significant achievement in the treatment of this patient. Lesion size has been shown to be a diagnostic predictor of treatment success for osteonecrosis [20]. The reduction of the lesion size may indicate that the treatment has potential benefit and refinement of the dose and dosing schedule may be needed to optimize its effectiveness [3], [16].

\section{Conclusions}

Surgical decompression as mechanical and biological treatments results in decreased intraosseous pressure and enhanced osteogenesis in the osteonecrosis of femoral head SLE patients with prolonged use of corticosteroid. This effect could restrict the further development of cell death in osteonecrosis and the progression of the disease.

\section{Acknowledgments}

We would like to thank the staff of Klinik Bahasa FKKMK UGM for their help during manuscript preparation.

\section{References}

1. Liu Y, Liu S, Su X. Core decompression and implantation of bone marrow mononuclear cells with porous hydroxylapatite composite filler for the treatment of osteonecrosis of the femoral head. Arch Orthop Trauma Surg. 2013;133(1):125-33. https:// doi.org/10.1007/s00402-012-1623-3

PMid:23070224

2. Helbig L, Simank HG, Kroeber M, Schmidmaier G, Grützner PA, Guehring T. Core decompression combined with implantation of a demineralised bone matrix for non-traumatic osteonecrosis of the femoral head. Arch Orthop Trauma Surg. 2012;132(8):1095103. https://doi.org/10.1007/s00402-012-1526-3 PMid:22566110

3. Marker DR, Seyler TM, Ulrich SD, Srivastava S, Mont MA. Do modern techniques improve core decompression outcomes for hip osteonecrosis? Clin Orthop Relat Res. 2008;466(5):1093103. https://doi.org/10.1007/s11999-008-0184-9 PMid:18392909

4. Sen RK, Tripathy SK, Aggarwal S, Marwaha N, Sharma RR,
Khandelwal N. Early results of core decompression and autologous bone marrow mononuclear cells instillation in femoral head osteonecrosis: A randomized control study. J Arthroplasty. 2012;27(5):679-86. https://doi.org/10.1016/j.arth.2011.08.008 PMid:22000577

5. Rajagopal M, Balch Samora J, Ellis TJ. Efficacy of core decompression as treatment for osteonecrosis of the hip: A systematic review. HIP Int. 2012;22(5):489-93. https://doi. org/10.5301/hip.2012.9748

PMid:23100153

6. Morita D, Hasegawa Y, Okura T, Osawa Y, Ishiguro N. Longterm outcomes of transtrochanteric rotational osteotomy for non-traumatic osteonecrosis of the femoral head. Bone Joint $\mathrm{J}$. 2017;99-B(2):175-83. https://doi.org/10.1302/0301-620x.99b2. bjj-2016-0417.r2 PMid:28148658

7. Sultan AA, Khlopas A, Surace $P$, Samuel LT, Faour $M$, Sodhi N, et al. The use of non-vascularized bone grafts to treat osteonecrosis of the femoral head: Indications, techniques, and outcomes. Int Orthop. 2019;43(6):1315-20. https://doi. org/10.1007/s00264-018-4056-y

PMid:30039197

8. Al-Jabri T, Tan JY, Tong GY, Shenoy R, Kayani B, Parratt T, et al. The role of electrical stimulation in the management of avascular necrosis of the femoral head in adults: A systematic review. BMC Musculoskelet Disord. 2017;18(1):319. https://doi. org/10.1186/s12891-017-1663-5

PMiD:28754159

9. Zhao D, Huang S, Lu F, Wang B, Yang L, Qin L. Vascularized bone grafting fixed by biodegradable magnesium screw for treating osteonecrosis of the femoral head. Biomaterials. 2016;81:84-92. https://doi.org/10.1016/j.biomaterials.2015.11.038

PMid:26724456

10. Ohzono K, Saito M, Takaoka K, Ono K, Saito S, Nishina T, Kadowaki T. Natural history of nontraumatic avascular necrosis of the femoral head. J Bone Joint Surg Br. 1991;73(1):68-72. https://doi.org/10.1302/0301-620x.73b1.1991778 PMid:1991778

11. Mont MA, Carbone JJ, Fairbank AC. Core decompression versus nonoperative management for osteonecrosis of the hip. Clin Orthop Relat Res. 1996;324:169-78. https://doi. org/10.1097/00003086-199603000-00020 PMid:8595753

12. Stulberg BN, Davis AW, Bauer TW, Levine M, Easley $\mathrm{K}$. Osteonecrosis of the femoral head. A prospective randomized treatment protocol. Clin Orthop Relat Res. 1991;268:140-51. PMid:2060201

13. Shah SN, Kapoor CS, Jhaveri MR, Golwala PP, Patel S. Analysis of outcome of avascular necrosis of femoral head treated by core decompression and bone grafting. J Clin Orthop Trauma. 2015;6(3):160-6. https://doi.org/10.1016/j.jcot.2015.03.008 PMid:26155051

14. Persiani P, De Cristo C, Graci J, Noia G, Gurzì M, Villani C. Stage-related results in treatment of hip osteonecrosis with core-decompression and autologous mesenchymal stem cells. Acta Orthop Belg. 2015;81(3):406-12. PMid:26435234

15. Kiaer T, Pedersen NW, Kristensen KD, Starklint H. Intraosseous pressure and oxygen tension in avascular necrosis and osteoarthritis of the hip. J Bone Joint Surg Br. 1990;72(6):102330. https://doi.org/10.1302/0301-620x.72b6.2246284 PMid:2246284

16. Saw KY, Hussin P, Loke SC, Azam M, Chen HC, Tay YG, et al Articular cartilage regeneration with autologous marrow aspirate 
and hyaluronic acid: An experimental study in a goat model. Arthroscopy. 2009;25(12):1391-400. https://doi.org/10.1016/j. arthro.2009.07.011

PMid:19962065

17. Wang W, Chen Q, Li X, Zhang W, Peng L, Wang L, et al. Enhancement of bone formation with a synthetic matrix containing bone morphogenetic protein-2 by the addition of calcium citrate. Knee Surg Sports Traumatol Arthrosc. 2013;21(2):456-65. https://doi.org/10.1007/s00167-012-1953-2 PMid:22434160

18. Wahl DA, Czernuszka JT. Collagen-hydroxyapatite composites for hard tissue repair. Eur Cell Mater. 2006;11:43-56.
PMid:16568401

19. van der Stok J, Hartholt KA, Schoenmakers DA, Arts JJ. The available evidence on demineralised bone matrix in trauma and orthopaedic surgery: A systematic review. Bone Joint Res. 2017;6(7):423-32. https://doi.org/10.1302/2046-3758.67.bjr2017-0027.r1

PMid:28733366

20. Jones LC, Hungerford MW, Khanuja HS, Hungerford DS. Outcome measures for evaluation of treatments for osteonecrosis. Orthop Clin North Am. 2009;40(2):179-91. https://doi.org/10.1016/j.ocl.2008.10.005

PMid:19358904 